\title{
On Linguistic Landscape in Language Service at Da Li Ancient City, China
}

\author{
Xing $\mathrm{Lu}$ \\ Udayana University, Denpasar, Indonesia \\ I Nengah Sudipa \\ Udayana University, Denpasar, Indonesia \\ Ketut Artawa \\ Udayana University, Denpasar, Indonesia \\ I Made Suastra \\ Udayana University, Denpasar, Indonesia
}

\begin{abstract}
This study aims to research the language service of the linguistic landscape in Da Li ancient city, China. In order to achieve research goal, the research questions are put forward. (1) What kind of language service does the linguistic landscape provide in the study area? (2) How does the linguistic landscape provide the language service in the study area? The data sources are collected from most densely populated places with large population flow and the uncertain source of the people to make the study more reliability and validity. The methods of data collection mainly are observation and interview. The techniques of data analysis combined descriptive quantitative and qualitative analysis. The result showed that the linguistic landscape in Da Li mainly belongs to the text service, which took the language written on public signs as a carrier to implement language service. The linguistic landscape in the study area provides double-sided language service to both sign owners and readers.
\end{abstract}

Index Terms - language service, linguistic landscape, language economics, Da Li ancient city

\section{INTRODUCTION}

In a commercialized society, as a special commodity, language is endowed with certain economic value while carrying culture and transmitting information, thus forming a language industry. In addition to economic value, the language industry also has social value, which is mainly reflected in "serving language life and assisting language policy"(Ripei Zhang, 2018). The language industry provides language products and language services for people. In a narrow sense, they refer to language textbooks, audio products, language training and language translation services. With the development of language industry, the conceptual scope of language products and language services has broadened.

Language product forms that take language as the core element or dominant element to meet certain needs, including language publishing, language training, language translation, language testing, language information processing, language arts, language rehabilitation, language exhibitions, etc (Latupeirissa et al., 2019). Products are classified as language products (Yan $\mathrm{Li}, 2017$ ). Language services have also broadened the scope of definition. In a broad sense, language services refer to services that use language (including text), language knowledge, language art, language technology, language standards, language data, language products and other language derivatives to meet the needs of the government, society, families, and individuals (Yuming Li, 2014; Dan \& Septevany, 2020).

This research takes the linguistic landscape from center area of $\mathrm{Da} \mathrm{Li}$ ancient city tourist attractions, China as the investigation object. Based on the language service theory, a theoretical framework is proposed to deeply explore the language service consciousness on public signs in tourist attractions by emphasizing the tool effectiveness and economic effectiveness of the language landscape.

\section{LITERATURE REVIEW}

As early as 1986, the Chinese Language and Writing Conference mentioned that it is necessary to strengthen the basic and applied research of language, and do a good job in social surveys and social consultation and service. This can be regarded as China's first request for language work from the perspective of language service. At that time, the definition of the concept of language service has been limited to only language training and language translation service. With the growing awareness of interdisciplinary research and the in-depth development of linguistic research itself, it is not until the last decade that Chinese scholars have gradually broadened the scope of language service 
research. Yuming Li first proposed a specific language service concept in 2010, and then Shaobing Qu also sorted out and thought about language service issues and achieved certain research results.

Raymond Boudon's (2008) "good-reasons” explains the public's behavior. The main contribution to contemporary methodological debates is his definition of methodological individualism as logic of explanation. In his opinion, social phenomena must be explained in terms of intentional and particularly unintentional consequences of the aggregation of human actions dictated by "good reasons". Boudon's approach can be divided into two complementary stages: the explanation of action, and the explanation of its consequences. The relevance is that it studied the behavior by linguistic landscape research and took the public needs into consideration. He mainly explained the people's behavior which is a different and new perspective to study linguistic landscape. However he ignored to take the consideration of language policy or the binding force of the official regulation or maybe economic factor, which all could have an influence on the behavior.

Spolsky. B (2009) argues that linguistic landscape is a valuable tool for exploring and embodying urban multilingual ecology and for studying language choices. He believes written language is more suitable for communication in public area than spoken language. He mainly introduced the use of advertising language in public places. The range of linguistic landscape in the study of Spolsky, B. (2009) is much broader than the general understanding. He enriched the scope of linguistic landscape research but the theoretical explanation is not sufficient because the whole article mainly focuses on language management rather than outdoor media. The relevance with this study is that it emphasis on the language choice on linguistic landscape, which mentioned as code preference in this study. The strength is that he explained the multilingual was the representative of urban language ecology demonstrated a more important role for linguistic landscape research. However he ignored to explore the economic function of language on the public signs, which is also an important part for the study.

E. Shohamy and D. Gorter (2009) take a different approach to the study of the linguistic landscape by applying one of the methods used in the economic study of biodiversity. This approach does not go against other approaches taken so far but it is an additional contribution to understanding the nature of language signs. The economic approach focuses on the market and non-market value of the linguistic landscape. According to the research, they boldly speculate that another possibility for future research is to ask different groups of people about their willingness to pay for the use of specific languages in the linguistic landscape or for maintaining and promoting linguistic diversity. E.Shohamy \& D. Gorter is the first who attempt to define the non-market value of the linguistic landscape in the study of LL. It's not like Claus (2002) does in the research of LL with the market value by looking at the number of exposures, the value of the location and the revenues of language signs in the linguistic landscape. The measurement of the non-market value is made by looking at the use and non-use value of the language signs. However, this method is still in the primary stage and there isn't a lot of empirical research, so the stability and universality remains to be seen.

Elana Shohamy, Eliezer Ben-Rafael, Monica Barni (2010) used sociological related theories to study linguistic landscape. Ben-Rafael sums up the four principles of language construction, namely the "presentation of self" first proposed by Goffman. The relevance with this study is Ben-Rafael and Shohamy used linguistic landscape theory to explain the overall language distribution of the place and the local language distribution of each study and top-down, in the linguistic landscape as a symbolic construction of the Israeli public space, which is used also in this paper in studying the tool function of linguistic landscape in Da Li. The strength was Shohamy analyzed social life from the perspective of actors using their established words to show others their favorable image. And In the textual framework of Ben-Rafael the linguistic order phenomenon with unofficial logos. The characteristics of language are used in the linguistic landscape in the bottom-up and different active areas. The weakness is their study paid much attention on tool and meaning function of urban settings, which lack consider the economic function of linguistic landscape. They aspire to delve into linguistic landscape beyond its appearance as a jungle of jumbled and irregular items by focusing on the variations in linguistic landscape configurations and recognizing that it is but one more field of the shaping of social reality under diverse, uncoordinated and possibly incongruent structuration principles.

Shaobing Qu (2016) defined the concept of language service. Language service can be divided into different sections such as text, voice, vocabulary, and grammar. Each section can be independently associated with language service. This association can occur at various levels and links of language service from planning to practice. For the reference, it provides the general theory to this study and the language service is a comprehensive concept including any service aspects language-related. However, this study as a research on linguistic landscape can broaden the scope of application of language service theory, and provide new perspectives and ideas for linguistic landscape research.

During last ten years linguistic landscape research has developed quite significantly with the efforts of linguists and scholars. Signage in the public space was at first investigated as a curiosity, later as an additional perspective in other studies. Gradually researchers started to explore issues specifically related to the LL. The emerging methodological issues led to the development of some sort of methodology for the field (Chrismi-Rinda Loth, 2016). Although there is no unified research standard in the academia on stipulating how to conduct a linguistic landscape survey in a certain area. However, at least some consensus has been reached in academia.

In recent years, besides studying the language structure, multilingual situation, language translation of public signs, and the use of minority languages, the linguistic landscape itself, and many Chinese scholars have paid more attention to the economic function, service function, and social function of the linguistic landscape. These research results enrich 
the functionality of linguistic landscape research, broaden the boundaries of linguistic landscape research, and provide more theoretical support and available data for related research but almost no one mentioned to study the linguistic landscape with the perspective of language service. Therefore, applying language service theory provides linguistic landscape research a new way.

\section{RESEARCH METHODOLOGY}

This research mainly adopts quantitative and qualitative combined method to study the language service effectiveness system. Quantitative analysis mainly studies the linguistic landscapes been collected in the study area and qualitative analysis is mainly used in interview research. Qualitative research aims to introduce the original intention of language service providers to make language signs in the language environment.

\section{A. Sample and Participants}

The sampling area are located in densely populated places with the biggest feature of the area is the large population flow, the source of these people is uncertain, and signs of high density can usually be found there. Based on these characteristics, the linguistic landscape of these regions must be more representative, and research based on data collection must be more convincing. The participants are the linguistic landscape users in the research area. This study obtains permission to interview 136 public signs owners, including 5 official managers and 131 shop owners. Record and analyze the content of interviews to examine the tool effectiveness and economic effectiveness of language service. In order to collect a more comprehensive and extensive opinions, this study does not distinguish the participants' identity, gender, age, nationality, etc.

\section{B. Instruments}

The equipment used in this study is a digital camera and a digital voice recorder. The data of this study is photos and recordings of interview. The quantitative analysis mainly studies the photos and the qualitative analysis is the study of interviews.

\section{Data collection and Analysis}

The data collecting of this study is not confined to any particular type of signs. In order to get the diversity of linguistic landscape, a wide range of signs are selected rather than a specific sign, which would enhance the reliability. Backhaus (2007) also supports this point of view, as he stated that: If we only focus on one kind of sign, we cannot get the characteristic of the whole city. The method of data collecting is the comprehensive photographing of signs in various shops, hotels restaurants at the streets of survey area.

In order to understand the type of language service and the way linguistic landscape proving in the study area, the data analysis is carried out under the framework of language service theory. Quantitative analysis began by calculating the ratio of different types of signs in the survey area. The functions of the language service are carried out, which is a qualitative analysis and includes the research method of language economics. In the last, according to the observation and interview the research questions are answered. If there is any problem or advantage, it would also put forward into discussion.

\section{RESULT AND DISCUSSION}

After delineating the scope of data collection, a digital camera is used to photograph and record all public signs in the area, and a total of 1722 linguistic landscapes were counted. According to the classification methods commonly used in linguistic landscape research, the collected samples can be divided into official signs (top-down) and private signs (bottom-up).

In this research, a special type of sign is also found to be a combination which is private signs set up on official signs. This is special because it belongs to the government, but the theme and code preference is private.

TABLE 1

\begin{tabular}{cc} 
CLASSIFICATION AND QUANTITY STATISTICS \\
\hline Linguistic landscape & Amount \\
\hline Top-down & 235 \\
Bottom-up & 1185 \\
Combined & 302 \\
\hline
\end{tabular}

(1) A total of 235 official signs are counted, which refer to signs of an official nature established by the government, such as street signs, street names, building names, etc., which are also often called top-down signs. Since the creators of such signs are generally organizations that implement local or central policies, the language of signs represents the government's position and behaviour.

(2) A total of 1185 private signs are counted. They are signs set up by private individuals or companies for commercial or information introduction, such as store names, billboards, posters, etc., which are usually called bottom- 
up signs or unofficial signs. Since private sign is subject to relatively few restrictions and language usage is relatively free, it can more truly reflect the social language composition of a region.

(3) There are a total of 302 official and private combined signs. The official selects the location and presentation method of the sign, and private individuals apply for the use or rent it to provide language service. This form appears in the location of trash cans and road signs in the tourist area, which combines the unity of official signs and the diversity of private signs.
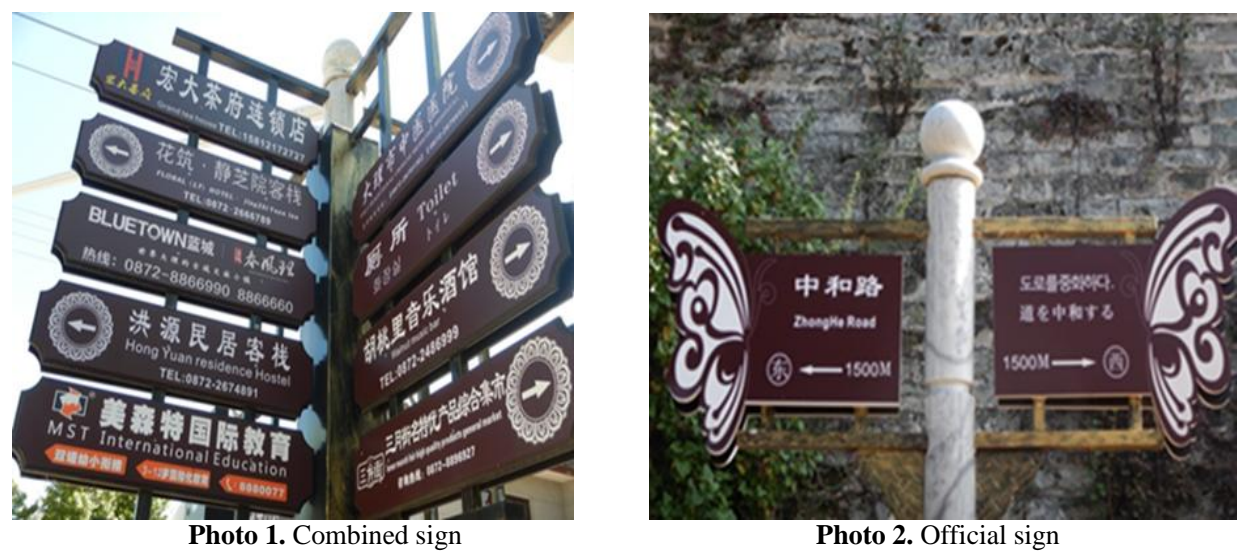

Photo 2. Official sign

Linguistic landscape research mainly studies the symbols (both language and non-verbal resources) used on public signs. And the language service theory believes all the services provide by language must including two parts the tool effectiveness and the economic effectiveness. As language itself is a communication instrument, the tool effectiveness is the fundamental of language service and all of the services could create benefits the economic effectiveness is the purpose of language service.

\section{A. Tool Effectiveness of Linguistic Landscape}

Basically, linguistic landscape is one of the easiest and most effective ways of spreading because it's text-based and not restricted by time and space for information dissemination. The diversity of information gives different communication functions to the linguistic landscape, thereby providing language service based on different purposes. The tool effectiveness of linguistic landscape is mainly reflected in the following three points: 1. A tool of information transmission. 2. A tool of interpersonal interaction. 3. A tool of cultural display.

\section{Information Transmission}

The public signs always combine the needs of the target audience and sign owners based on different construction principles to form a proprietary industry language. If a sign wants to find the best balance between the target audience and its own purpose, it must choose the language used, which is the first problem for sign owners to solve. Introducing services and providing information are also the most important and intuitive functions of signs.

The official sign provides a non-profit information service. By interviewing the official sign managers, it can be seen that the language orientation of this type mainly considers the service object. Signs set up for the purpose of serving tourists who visit $\mathrm{Da} \mathrm{Li}$ are generally at least bilingual (Chinese and English). Signs serving local residents use monolingual, with more eye-catching and meaningful pictures to enrich the information expression of the signs. All official signs present the signs of cities and scenic spots in different ways, in order to realize the branding of the city, which can leave a deep impression on people and create a unique city image.

For the private sign owners, regardless of the type the owner regards the sign of their stores as a tool to promote the store and attract customers. Nevertheless, due to the strong subjectivity of private sign language code selection, there are different manifestations of information. The first commonly used on the signs are brand logos which serve the shop owners to promote the brand, then the service information serve the sign readers to find the service they are looking for, last the photo or phone numbers for the purpose of providing the eye-catching service. The combined sign has the "appearance" of the official sign and the "content" of the private sign. The emplacement and inscription are inclined to be as same as official sign but the code preference are more likely consistent with private sign.

\section{Interpersonal Interaction}

The interactivity is the process of realizing the interaction and connection between the subject and the object based on psychology and physics. The service object of private sign is consumers, and the purpose is to realize direct communication with consumers through the presentation of language, thereby promoting consumption, which is completely consistent with the object and purpose of commercial advertising services. However, the service target and purpose of official sign may not be like that, because some official signs have the nature of voluntary service, such as road name signs and bus stop signs; some official signs are set up for non-profit purposes, such as public service billboards, etc. Therefore, more attention is paid to the accuracy and authority of information, and the interactivity of 
language is relatively less. There are also some indication signs that are officially set up to serve as reminders, warnings, prohibitions, and help functions. The choice of language codes for these signs is relatively more interactive.

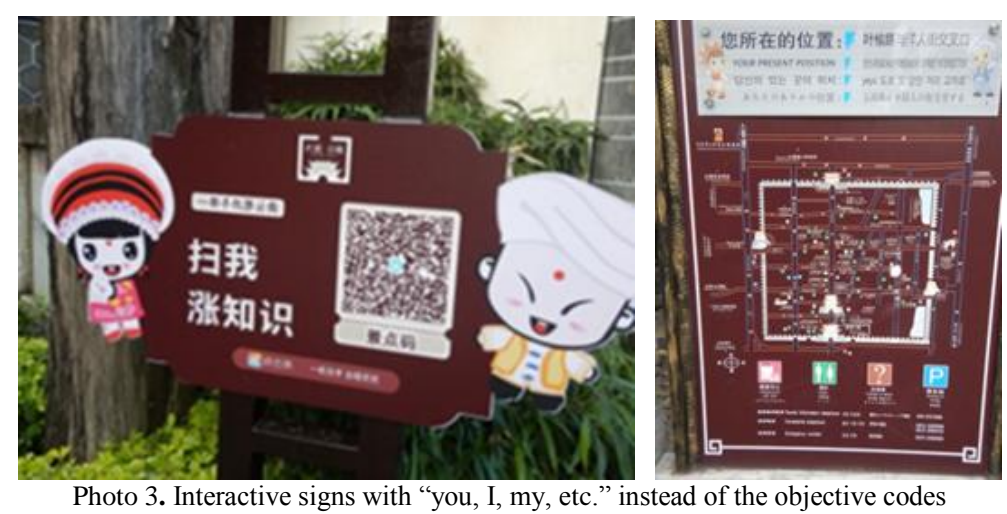

Most of the interactive signs are official signs (public service billboards) and part of combined signs, and the private signs account for the smallest proportion. According to the interview records, the sign users mainly choose the language by determining the purpose of sign service, and carry out the overall design. Signs mainly serving information transmission are generally not interactive. The purpose of general service of interactive signs is to guide readers to conduct personal norms or provide audio-visual services. The audio-visual services include introductions to scenic spots, cultural introductions, etc., which are spread to readers in the form of voice, video or pictures. This new type of service provided by linguistic landscape is due to the popularity and application of QR codes.

\section{Culture Display}

It is found that the linguistic landscape in the study area also used as cultural expressions and it can be divided into three types after analyzing the recording of interviews with sign owners.

(1) Cultural identity. It refers to the affirmation of the most significant things of the nation formed by people living together for a long time in a national community. The core is the identity of the basic values of a nation. It is the spiritual bond that unites this national community and the spiritual foundation for the continuation of the life of this national community. Cultural identity is an important foundation of national identity and it is the deepest foundation.

(2) National aesthetics. It refers to the unique structure of a nation's aesthetic taste, aesthetic ability, and aesthetic ideals that distinguish it from other nations. Due to factors such as specific living conditions, lifestyle, natural environment and ancestry inheritance, all classes, groups and individuals of a nation have a common and relatively stable aesthetic consciousness and national character. This commonality is often presented in the aesthetic practice of ethnic members as the overall function of the system. In the linguistic landscape, the font size, code preference, the material of the sign, and the brightness of the color tone on the signs all directly or laterally reflect the aesthetic characteristics of the local peoples.

(3) Regional image. It refers to the overall impression and overall evaluation of a region in the minds of the public. Linguistic landscape is a manifestation of soft image. The language, code sequence, and representative regional logo appearing on the signs are all cultural symbols that display the regional image.

\section{B. Economic Effectiveness of Linguistic Landscape}

All the linguistic landscape can produce certain economic effects, but the process and methods of converting language service into economic benefits are different. The official sign does not aim at profit gains, but during its language service, it has a wide range of influences, thereby indirectly and laterally promoting economic. Such economic benefits may not be immediate, and the beneficiaries are not the government that set up language signs, but may be shops or residents in this area. The good reputation of this city brought by the linguistic landscape is also a kind of economic benefit in disguise, and it is sustainable. The specific performance can be represented by the following: 
TABLE 2

ECONOMIC TRANSFORMATION OF OFFICIAL SIGNS

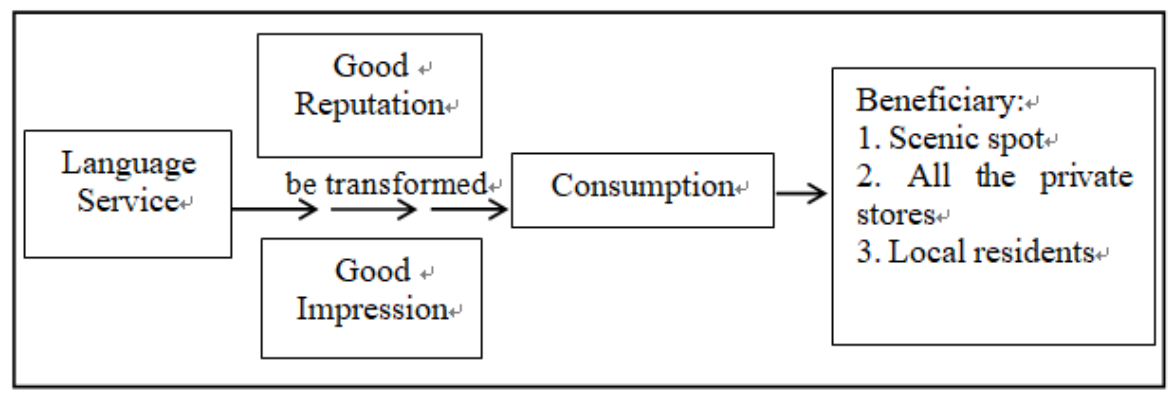

Different from the economic transformation process of the official signs, the private signs and combined signs are essentially realize economic benefits through the information transmitted on the public signs. Private signs have direct economic benefits due to the advantages of placement context, while combined signs help owners achieve economic benefits in an indirect way. The specific performance is shown below:

TABLE 3

ECONOMIC TRANSFORMATION OF PRIVATE \& COMBINED SIGNS

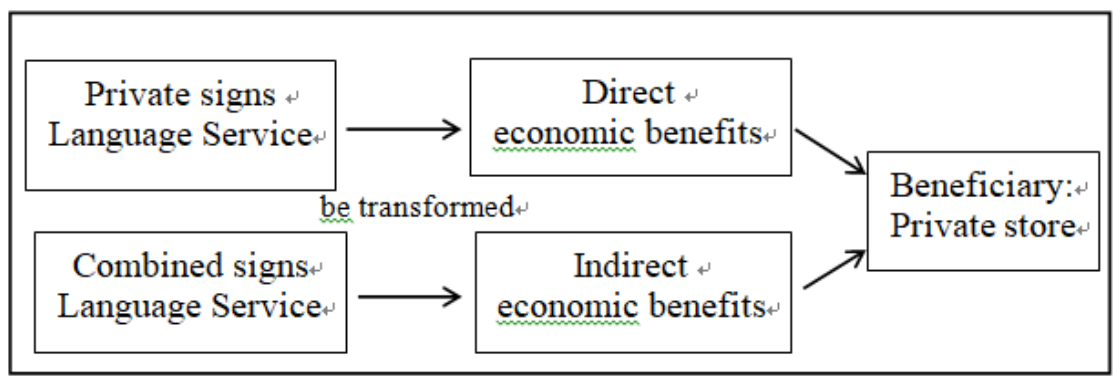

It is clear that the economic beneficiaries of official signs are not the government itself, and such signs are not established for the purpose of economic gain. Due to the limitation of the placement context, the combined signs cannot achieve direct economic benefits, and can only be used as one of the influencing factors to achieve economic behavior. Therefore, it is not included in the scope of discussion. The following analyzes the economic effectiveness of the language signs from the costs and benefits, supply and demand, efficiency and fairness of language signs.

\section{Costs and Benefits}

For any language-related investment, maximizing returns and minimizing costs are the goals pursued by investors. The language of the official signs in $\mathrm{Da} \mathrm{Li}$ is mainly Chinese, with English, Japanese, and Korean. This government behavior demonstrates the official language could of official signs, and the purpose of language selection is to strengthen the dominant position and discourse power of the country's dominant language.

Private signs are mostly for the purpose of economic efficiency in terms of language selection: merchants use one or several languages on the signs to convey product or service information to attract customers to consume and obtain economic benefits. Da Li has clear sign specifications in the design of private signs, emphasizing the color and size. This mandatory policy reduces the autonomy of enterprises and stores in sign selection. Private owners who ignore this policy may incur penalties from the regulatory authorities and damage their own interests, which will invisibly increase the investment costs.

Nevertheless, the government adopts an implicit signage policy in terms of language selection, and does not intervene in the language selection on signs of enterprises and stores. The private sign owners have full autonomy in the deployment of language resources, which is conducive to businessmen's realization of economic benefits and noneconomic goals (Such as emotional needs, identity recognition, etc.) through language selection and creativity, and provides a guarantee for businesses to pursue maximum benefits. And the government has also adopted encouraging economic intervention, and given certain economic subsidies to merchants who use the sign in a uniform style according to regulations and requirements. This intervention also dazzled the study area, and the various private signs that do not match the theme of "Ancient City" formed a unified style. It brings consumers a more comfortable and more appropriate sightseeing experience, thereby promoting tourism consumption in the city, realizing the purpose of language services, and obtaining certain economic benefits at the same time.

The establishment of combined signs must first be applied by private shops to the city management department, after approved, and then paid for a certain service fee and sign production fee before it can be put into use. Relatively speaking, the cost is higher, but the audience's radiation surface is wider than that of private signs that only appear in shops. 


\section{Supply and Demand}

In order to cater to the international market, the official signs of $\mathrm{Da} \mathrm{Li} \mathrm{linguistic} \mathrm{landscape} \mathrm{tend} \mathrm{to} \mathrm{adopt} \mathrm{at} \mathrm{least}$ bilingual supply in Chinese and English to enhance the competitiveness of the city. Some signs of special service demand also adopt the supply of Chinese, English, Japanese, and Korean. However, Chinese has an absolute advantage, and the writing of Chinese characters uses modern standard simplified characters. This multilingual supply mode is typically set up driven by consumer demand, especially Japanese and Korean can be selected as the code displayed on official signs among many foreign languages. It is also calculated by the government based on the big data on the number of foreign tourists in the past ten years. For government departments, the ratio of supply cost to utility is acceptable within a certain range. Demand drives supply, and supply provides more options for demand. The specific performance is shown below:

TABLE 4

LANGUAGE SuPPLy AND DEMAND OF OFFICIAL SignS

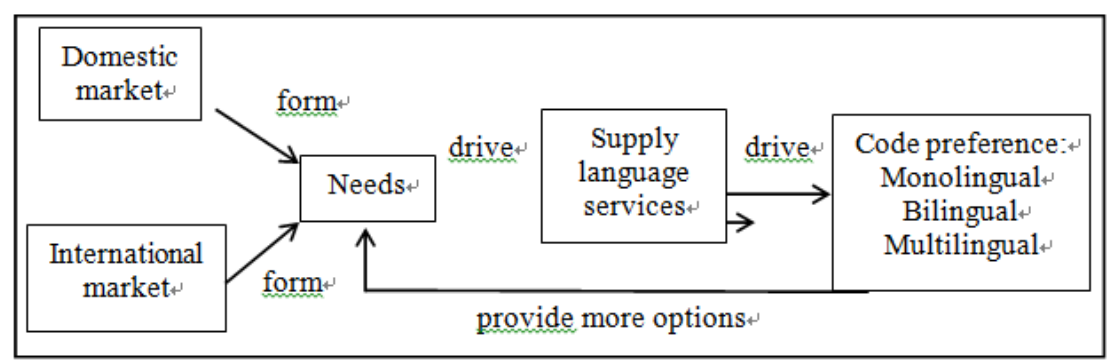

Compared to the official sign demand-oriented language service supply consciousness, in terms of private sign, the supply of language is slightly monotonous. The main reason is that the language of private shops is not oriented by market demand, but from the perspective of the needs of the merchants to transmit information. Through interviews, many shop owners believe that signage is one of the ways to promote products and provide service information, not the only way. Consumers can get the necessary product information through the open space environment of the store or the audio and video advertisements played in a loop by the store. They believe that no matter what language uses, it cannot fully meet the needs and choices of all consumers with different purposes and backgrounds. Using sign as a tool to assist shops in introducing products or services can instead attract consumers with corresponding consumer willingness. The specific performance is shown below:

TABLE 5

Language Supply And Demand Of Private Sign ANd Combined Sign

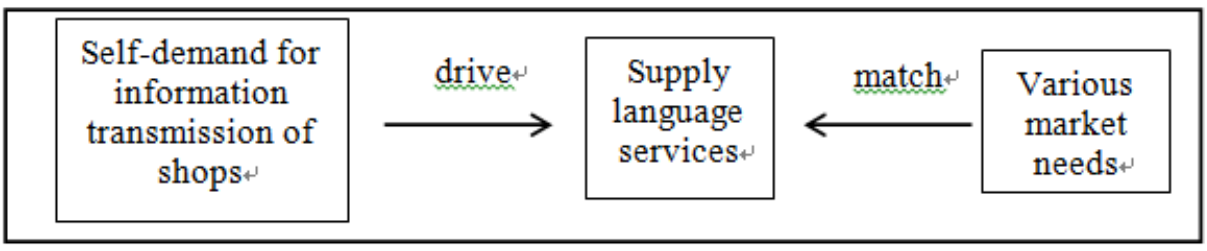

\section{Efficiency and Fairness}

On the official signs of the tourist attractions in Da Li Ancient City, especially the road signs with the highest concentration of multilingual phenomena, for fairness, both Chinese and foreign languages appear together at the same time. In order to reflect the efficiency of language services, two boards are used to indicate the four Languages. Although Chinese has a certain code priority on one of the signs, the foreign language on the other sign also enjoys the same priority as Chinese. This approach is to achieve the efficiency of language services while ensuring fairness as much as possible. However, due to the cost, this fairness is also limited. It does not cover all the official signs and has not been adopted in signs for other language service purposes.

Using a country's dominant language or a combination of "national language or official language + service target language" can meet the needs of most people. Although this is unfair for minority language users, it is an efficient choice. In addition, even if several languages are placed side by side, the arrangement of languages will reflect the difference in order of importance according to the relationship of power. It can be seen that, like language power, complete equality is difficult to achieve in the construction of linguistic landscape. In the construction of private signs, most signs are at least bilingual.

However, it is not difficult to find that the status of Chinese and English languages on many signs can be described by the disparity. Due to the relevant laws and regulations and the physical environment of these linguistic landscapes, the power relationship and code order of Chinese are in the most conspicuous position in most cases, while English is like an embellishment and foil, in a marginal and inconspicuous position. Some don't even have pictures or logos that 
are clearly positioned. This also reflects that in order to ensure efficiency, the private signs in the city cannot fully take into account fairness. Combined signs are based on the requirements of official signs, while taking into account the information transmission of private signs. Generally speaking, efficiency is more important than fairness. The performance is shown below:

TABLE 6

COMPARISON OF EFFICIENCY AND FAIRNESS OF LINGUISTIC LANDSCAPE IN DA LI

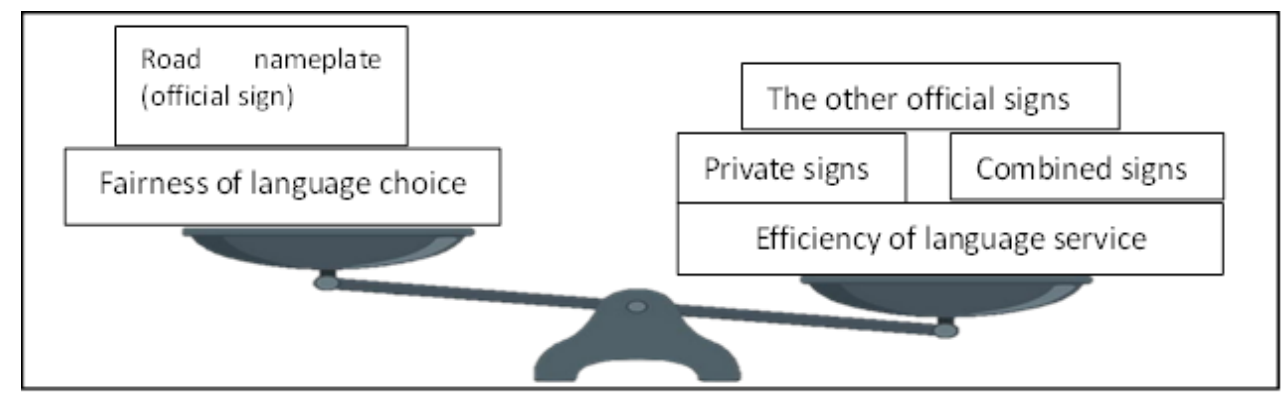

It is worth discussing that the service value of non-verbal resources should not be ignored. Sometimes they act more roles than language itself in language service of linguistic landscape. During the study, QR code and city logos are found in the official signs and combined signs, which provide convenient information accessing and formed a unique city image. The color used on both the signs and languages is also a special cultural symbol which better publicized the local cultural characteristics.

\section{CONCLUSION}

Based on the language service theory, the tool effectiveness and economic effectiveness of linguistic landscape in Da $\mathrm{Li}$ ancient city tourist attractions are studied and concluded as below. (1) According to the language form and characteristics, language service theory believes the language resources are composed by text, phonetics, vocabulary, and grammar. For the service of linguistic landscape in $\mathrm{Da} \mathrm{Li}$, it mainly belongs to the text service, which took the text or language written on public signs as a carrier to implement language service.

The dominant language is Chinese because of the Law of the People's Republic of China on the National Standard Language (2003) and Signboard Advertising Plan for Upgrading and Renovating Storefronts in Dali Ancient City (2018). English is used as a second language on any signs (official, private or combined) is also stipulated by the local regulations. The local government is in the hope of creating $\mathrm{Da} \mathrm{Li}$ as an internationalization and regionalization tourist destination. Although the sign owners and governors had the language service awareness in the construction of public sign, in the way of realization there are still many details worth noting. The wide use of Chinese and English is also out of economic considerations.

(2) The linguistic landscape in the study area provides double-sided language service to both sign owners and readers. On one hand, it provides information to the readers who are in need of the corresponding service. On the other hand, it provides economic profits to the sign owners whose ultimate purpose is to achieve profitability. The choice of colour, style, material and language of official signs provides service from a more far-sighted and overall perspective. However, the private signs and combined signs are mainly for personal economic interests, but complying with government and official regulations is the premise.

\section{ACKNOWLEDGMENTS}

The authors wish to thank the publisher for having reviewed and accepted this paper and also the suggestions from Prof. I Nengah Sudipa, Prof. Ketut Artawa and Prof. I Made Suastra.

\section{REFERENCES}

[1] Bernard Spolsky, Robert L. Cooper. (1991). The Languages of Jerusalem. Oxford Studies in Language Contact. Oxford: Oxford University Press.

[2] Backhaus, Peter. (2007). Linguistic landscapes: A comparative study of urban multilingualism in Tokyo. Clevedon [etc.]: Multilingual Matters.

[3] Chrismi-Rinda Loth. (2016). The linguistic landscape as construct of the public space: a case study of post-apartheid rural South Africa. Bloemfontein: University of the Free State.

[4] Collins, J. \& S. Slembrouck. (2007). Reading Shop Windows in Globalized Neighborhoods: Multilingual Literacy Practices and Indexicality. California: SAGE Journals, Journal of Literacy Research, 39:3, 335-356.

[5] Dan, L. D., \& Septevany, E. (2020). Interpretation of Taboos in Giving Gifts to Chinese People. The International Journal of Social Sciences World (TIJOSSW), 2(01), 75-84. 
[6] Du Plessis, T. (2011). Language visibility and language removal: a South African case study in linguistic landscape change. University of South Africa: Communication, 37(2): 194-224.

[7] Eliezer Ben-Rafael, Elana Shohamy, Muhammad H. Amara \& Nira Trumper-Hecht. (2006). Linguistic landscape as symbolic construction of the public space: The case of Israel. International Journal of Multilingualism 3(1). 7-30.

[8] E.Shohamy, D.Gorter. (2009). Language Economy and Linguistic Landscape. In book: Linguistic Landscape: Expanding the scenery, Publisher: Routledge, Editors: E.Shohamy \& D.Gorter. New York/London: Routledge, 55-69.

[9] Elana Shohamy, Eliezer Ben-Rafael, Monica Barni. (2010). Linguistic Landscape in the City. North Somerset: Multilingual Matters.

[10] Gorter, D. \& Cenoz, J. (2008). Knowledge about language and linguistic landscape. In N. Hornberger \& J. Cenoz (eds). Encyclopedia of Language and Education. 2nd ed. Vol. 6: Knowledge about Language. New York: Springer, 343-355.

[11] Hanauer, D.D. (2009). Science and the linguistic landscape: a genre analysis of representational wall space in a microbiology laboratory. In E. Shohamy \& D. Gorter (eds). Linguistic Landscape: Expanding the Scenery. New York/London: Routledge, 287-301.

[12] Junli Ge. (2016). Language and Space: A Perspective of Language Landscape Studies, Journal of Beijing International Studies University, (4) 68-80.

[13] Landry, R. \& R.Y. Bourhis. (1997). 'Linguistic Landscape and Ethnolinguistic Vitality: An Empirical Study' Journal of Language and Social Psychology, 16, 23-49.

[14] Latupeirissa, D. S., Laksana, I. K. D., Artawa, K., \& Sosiowati, I. G. A. G. (2019). On political language ideology: Critical view of Indonesian president speech. Journal of Language Teaching and Research, 10(4), 843-850.

[15] Ming Xu. (2017). The history and development trend of foreign language landscape research, Language Strategy Research, (2) 57-64.

[16] Peng Nie, Mu Nai Reha. (2017). Investigation and Research on Yi Language Landscape in Xichang City. Language and writing applications (1) 70-79.

[17] Raymond Boudon. (2008). More on "good reasons": Reply to critics. International Studies in the Philosophy of Science, (7): 87-102.

[18] Ripei Zhang. (2018). The Ideas on Language Industry from the Perspective of Language Policy, Language Industry Research, (7) 24-30.

[19] Shaobing Qu. (1997). Advertising Language Strategy, Beijing: Science Popularization Press.

[20] Shaobing Qu. (2016). Introduction of Language Services. Beijing: The Commercial Press.

[21] Scollon, R. \& S.W. Scollon. (2003). Discourses in Place: Language in the material world. London \& New York: Routledge.

[22] Shohamy, S. \& D. Gorter (eds.) (2009). Linguistic Landscape: Expanding the Scenery. Oxon \& New York: Routledge.

[23] Spolsky, B. (2009). Language Management. Cambridge: Cambridge University Press.

[24] Xiaofei Deng. (2015). Comparative analysis of the language landscape between Yuyuan Business City and Shanghai Old Street, Modern Chinese (Language Research Edition), (10) 31-35.

[25] Xing Lu, I Nengah Sudipa, I Ketut Artawa, I Made Suastra. (2021). The Linguistic Landscape of Dali Ancient City, China: A Geosemiotics Approach, The International Journal of Language and Cultural, Growing Scholar Publishing Online, (Vol.3) 4655. Retrieved on May 6, 2021 from: https://www.growingscholar.org/journal/index.php/TIJOLAC DOI: https://doi.org/10.5281/zenodo.4707337

[26] Yuanbing Duan. (2016). Linguistic landscape research under the background of globalization: a new approach to multilingual research, Hunan Social Sciences, (2) 43-48.

[27] Yuming Li. (2014). Language Service and Language Consumption, Education Guide, (Vol.7) 93-94.

[28] Yan Li. (2017). Language Consumption: Basic Theoretical Issues and Urgent Research Frameworks, Language Application, (4) $133-141$.

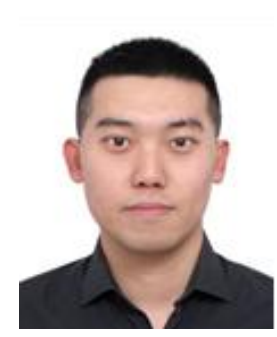

Xing Lu is a Doctor candidate. He was born in Henan, China, 1989. By 2012, he finished his Bachelor Degree from Tianjin Foreign Study University, major in English Language and Culture, Tianjin, China. In 2016 he got his Master Degree from Beihua University, Jilin, China, major in Education: Chinese Teaching. After that, he continued to Doctoral study program of Linguistics in Udayana University, Denpasar, Indonesia.

As visiting scholar, he was teaching Chinese language in Hasanuddin University, Makassar, Indonesia and Udayana University, Denpasar, Indonesia. Now he is teaching Chinese language in the University of Cyprus, Nicosia, Cyprus. He is interested in the study of both teaching Chinese as a foreign language and sociolinguistics. He has published An Analysis on Student's Chinese Learning Needs of Confucius Institute at Hasanuddin University, Indonesia, Journal of Contemporary Educational Research, Sydney: Bio-Byword Scientific Publishing Pty. Ltd., Australia. The Linguistic Landscape of Dali Ancient City, China: A Geosemiotics Approach, The International Journal of Language and Cultural, Growing Scholar Publishing Online and so on. 


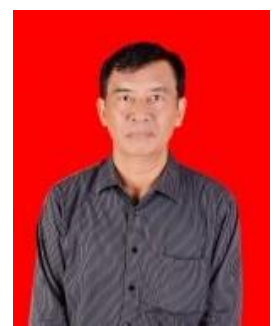

I Nengah Sudipa is a linguistics professor who was born in Pesangkan Duda Timur, Selat, Karangasem, Bali, 31 July 1954. He graduated from the Department of English Language and Literature Udayana University, Denpasar, Indonesia (1981), Master of Arts (MA) from Linguistics Department of Monash UniversityMelbourne Australia (1988), Doctoral degree (S3) obtained at the Linguistics Program Studies, Udayana University, Denpasar, Indonesia (2004). Once he occupied the English Department Secretary, The vice Dean responsible for Administration and Finance, the chairman of Doctoral Program of Linguistics, Udayana University, and his current position is the chairman of the Faculty Senate. His research interests are Semantics and Psycholinguistics and he has published a number of various books dealing with Balinese Verbs, Semantics, Micro linguistics and Indonesia language for International students.

Prof. Sudipa published the article The Development of Syllabus and Lesson Plan Based on English for Occupational Purposes, London: International Journal of Psychosocial Rehabilitation, United Kingdom, 2020. Ngaba and makta of balinese action verbs, How to map their meanings, Center for Promoting Ideas (CPI), USA, 2019.

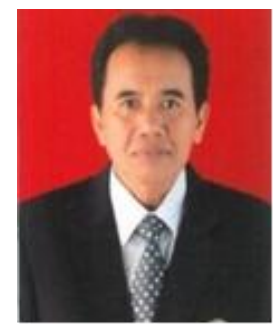

Ketut Artawa is a linguistics professor. He has joined the English Department Udayana University since 1983. His educational background included a bachelor degree (BA) and doctorandus (Drs.) degree in English language and literature from Udayana University, MA degree in Linguistics graduated on the first day of June 1992 and $\mathrm{PhD}$ degree in Linguistics graduated on the twenty-fourth day of March 1995 from La Trobe University.

He was awarded an outstanding lecturer by the Faculty of Letters in 1997 and Udayana University in the same year and he obtained his professorship in Linguistics in 2005. His administrative experiences include Head of the English Extension Program (1997-2004), Head of Linguistics Masters Study Program (20032007), Head of Linguistics Doctoral Study Program (2008-2012), and Vice Dean for Academic Affairs (20122015). He is currently the Head of Linguistics Doctoral Study Program (since 2018).

Prof. Artawa was a visiting Professor at the Research School of Pacific Studies, the Australian National University (October 2009January 2010) and a Visiting Professor at the Research Institute for Languages and Cultures of Asia and Africa (ILCAA/ AA-ken), Tokyo University of Foreign Studies (TUFS), Japan (2011-2012). He was involved in the international research project entitled "Austronesian voice systems: an eastern Indonesian perspective" which was funded by National Science Foundation headed by Prof. M. Shibatani from Rice University, USA. (2006-2011). With regard to supervising graduate students; until Mei 2020, as a main supervisor, He has supervised $20 \mathrm{PhD}$ graduates in Linguistics and as co-supervisor of $8 \mathrm{PhD}$ graduates.

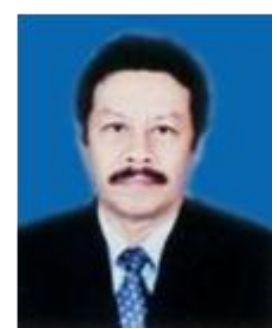

I Made Suastra obtained his postgraduate diploma in TEFL, Master in Applied Linguistics at Sidney University in 1988, Australia, and his Doctorate of Linguistics at La Trobe University in Melbourne, Victoria, Australia (1996).

$\mathrm{He}$ is a professor of Sociolinguistics at Udayana University, Denpasar. He has been a supervisor for numerous theses and doctorate dissertation. He has actively participated in numerous national and international conferences and published books and articles related to linguistics and applied linguistics. Prof. Suastra's Scopus Author ID: https://www.scopus.com/authid/detail.uri?authorId=57208123511 and Google Scholar ID: https://scholar.google.co.id/citations?user=mpQnmOkAAAAJ\&hl=id 